\title{
Does Dehydration Affect the Adaptations of Plasma Volume, Heart Rate, Internal Body Temperature, and Sweat Rate During the Induction Phase of Heat Acclimation?
}

\author{
Yasuki Sekiguchi, Erica M. Filep, Courteney L. Benjamin, Douglas J. Casa, and Lindsay J. DiStefano
}

Clinical Scenario: Exercise in the heat can lead to performance decrements and increase the risk of heat illness. Heat acclimation refers to the systematic and gradual increase in exercise in a controlled, laboratory environment. Increased duration and intensity of exercise in the heat positively affects physiological responses, such as higher sweat rate, plasma volume expansion, decreased heart rate, and lower internal body temperature. Many heat acclimation studies have examined the hydration status of the subjects exercising in the heat. Some of the physiological responses that are desired to elicit heat acclimation (ie, higher heart rate and internal body temperature) are exacerbated in a dehydrated state. Thus, euhydration (optimal hydration) and dehydration trials during heat acclimation induction have been conducted to determine if there are additional benefits to dehydrated exercise trials on physiological adaptations. However, there is still much debate over hydration status and its effect on heat acclimation. Clinical Question: Does dehydration affect the adaptations of plasma volume, heart rate, internal body temperature, skin temperature, and sweat rate during the induction phase of heat acclimation? Summary of Findings: There were no observed differences in plasma volume, internal body temperature, and skin temperature following heat acclimation in this critically appraised topic. One study found an increase in sweat rate and another study indicated greater changes in heart rate following heat acclimation with dehydration. Aside from these findings, all 4 trials did not observe statistically significant differences in euhydrated and dehydrated heat acclimation trials. Clinical Bottom Line: There is minimal evidence to suggest that hydration status affects heat acclimation induction. In the studies that met the inclusion criteria, there were no differences in plasma volume concentrations, internal body temperature, and skin temperature. Strength of Recommendation: Based on the Oxford Centre for Evidence-Based Medicine Scale, Level 2 evidence exists.

Keywords: hydration, physiological adaptations, heat exposure

\section{Clinical Scenario}

Exercise in the heat can lead to performance decrements and increase the risk of heat illness. ${ }^{1,2}$ Heat acclimation refers to the systematic and gradual increase in exercise in a controlled, laboratory environment with hot environmental conditions and is an impactful strategy that can be used to optimize performance and safety when exercising in the heat. ${ }^{1}$ Higher sweat rate, plasma volume expansion, decreased heart rate, and lower internal body temperature are observed following heat acclimation, and these adaptations decrease the risk of heat illness and increase exercise performance in the heat. ${ }^{1-3}$ Heat acclimation induction protocols typically occur over the course of 5 to 14 days ( $<7 \mathrm{~d}$, short term; 7-14 d, medium term; and $>14 \mathrm{~d}$, long term) and produce a variety of physiological gains in performance. ${ }^{1,3}$ Many heat acclimation studies have examined the hydration status of the subjects exercising in the heat ${ }^{4-8}$ and it is well known that hydration status impacts physiological and performance responses in the heat. ${ }^{9}$ Some of the physiological responses that are desired to elicit heat acclimation (ie, higher heart rate and internal body temperature) are exacerbated in a dehydrated state. ${ }^{10}$ Thus, euhydration (optimal hydration) and

The authors are with the Korey Stringer Institute, Department of Kinesiology, University of Connecticut, Storrs, CT. Sekiguchi (yasuki.sekiguchi@uconn. edu) is corresponding author. dehydration trials during heat acclimation induction have been conducted to determine if there are additional benefits to dehydrated exercise trials on plasma volume, heart rate, internal body temperature, skin temperature, and sweat rate. However, there is still much debate over hydration status and its effect on heat acclimation.

\section{Focused Clinical Question}

Does dehydration affect the adaptations of plasma volume, heart rate, internal body temperature, skin temperature, and sweat rate during the induction phase of heat acclimation?

\section{Search Strategy}

\section{Terms Used to Guide Search}

Our key terms included the following: hydration, heat, environment, acclimation, thermoregulation, and exercise.

- Patient/Client Group: regularly trained active males

- Intervention/Assessment: heat acclimation exercise sessions for 3+days

- Comparison: euhydration trial and dehydration trial

- Outcome: plasma volume, heart rate, internal body temperature, skin temperature, and sweat rate 
Table 1 Summary of Study Design and Articles Retrieved

\begin{tabular}{lll}
\hline Level of evidence & Study design & Reference \\
\hline 2 & Randomized controlled trial & Pethick et al \\
2 & Randomized controlled trial & Neal et al ${ }^{11}$ \\
2 & Randomized controlled trial & Schleh et $\mathrm{al}^{5}$ \\
2 & Randomized controlled trial & Garrett et al ${ }^{12}$ \\
\hline
\end{tabular}

\section{Source of Evidence Searched}

- PubMed

- Scopus

- SPORTDiscus

\section{Inclusion Criteria}

- Regularly trained active males

- At least one of the following dependent variables were included as dependent variables: plasma volume, heart rate, internal body temperature, skin temperature, and sweat rate

- There was an intervention of euhydration and dehydration

- Heat acclimation exercise sessions for 3+ days

- Full articles were published

\section{Exclusion Criteria}

- Heat acclimatization trials

- Studies not available in the English language

\section{Results of Search}

In the initial search, 5 out of 265 studies were recognized. Four of 5 studies met the inclusion criteria. One excluded study did not include the intervention of euhydration and dehydration. The study designs were 1 cross-sectional and 3 crossover studies. Each study was evaluated using the 2011 Oxford Centre for Evidence-Based Medicine (See Table 1).

\section{Best Evidence}

The studies in Table 2 were identified as the best evidence available for this critically appraised topic. All 4 studies had a level 2 evidence rating, because they were randomized control clinical trials, and the participant's $\mathrm{VO}_{2} \mathrm{max}$ was $\geq 53 \mathrm{~mL} \cdot \mathrm{kg}^{-1} \cdot \mathrm{min}^{-1}$ to identify them as "active" and "trained." At least one of following variables, including plasma volume, heart rate, internal body temperature, skin temperature, and sweat rate, was the dependent variable in all 4 studies. There were no differences in plasma volume, internal body temperature, and skin temperature following heat acclimation in all 4 studies. This is an indication that hydration status might not affect adaptations to heat acclimation.

\section{Clinical Bottom Line}

There is minimal literature assessing the effects of hydration status on heat acclimation induction. In the studies that met the inclusion criteria, there were no differences in plasma volume, internal body temperature, and skin temperature between euhydration and dehydration trials following heat acclimation. 5,6,11,12

Table 2 Characteristics of Included Studies

\begin{tabular}{|c|c|c|c|c|}
\hline Article & Pethick et al ${ }^{6}$ & Neal et al ${ }^{11}$ & ${\text { Schleh et } \mathrm{al}^{5}}^{5}$ & Garrett et al ${ }^{12}$ \\
\hline Design & RCT (cross-sectional study) & $\begin{array}{l}\text { RCT (balanced crossover } \\
\text { design) }\end{array}$ & RCT (random crossover design) & RCT (random crossover design) \\
\hline Participants & $\begin{array}{l}24 \text { subelite male athletes } \\
\text { Age, } 28(6) \mathrm{y} \\
\mathrm{BM}, 74.4(8.3) \mathrm{kg} \\
\mathrm{VO}_{2} \mathrm{max}, 61.2 \\
(7.0) \mathrm{mL} \cdot \mathrm{kg}^{-1} \cdot \mathrm{min}^{-1}\end{array}$ & $\begin{array}{l}8 \text { trained male athletes } \\
\text { Age, } 21(3) \mathrm{y} \\
\mathrm{BM}, 77.3(4.89) \mathrm{kg} \\
\mathrm{VO}_{2} \mathrm{max}, 56.9(7.2) \\
\mathrm{mL} \cdot \mathrm{kg}^{-1} \cdot \mathrm{min}^{-1}\end{array}$ & $\begin{array}{l}13 \text { recreationally active males } \\
\text { Age, } 23(1) \mathrm{y} \\
\mathrm{BM}, 81.4(2.2) \mathrm{kg} \\
\mathrm{VO}_{2} \mathrm{max}, 53.3 \\
(1.7) \mathrm{mL} \cdot \mathrm{kg}^{-1} \cdot \mathrm{min}^{-1}\end{array}$ & $\begin{array}{l}9 \text { trained males } \\
\text { Age, } 27(7) \mathrm{y} \\
\mathrm{BM}, 74.6(4.4) \mathrm{kg} \\
\mathrm{VO}_{2} \text { peak, } 60.0 \\
(7.0) \mathrm{mL} \cdot \mathrm{kg}^{-1} \cdot \mathrm{min}^{-1}\end{array}$ \\
\hline $\begin{array}{l}\text { Intervention } \\
\text { investigated }\end{array}$ & $\begin{array}{l}\text { EUH }(-0.2 \%[0.7 \%] \text { BML }) \\
\text { and DEH }(2.2 \%[0.5 \%] \\
\text { BML) groups performed } \\
90-\text { min exercise with iso- } \\
\text { thermal method in } 35^{\circ} \mathrm{C} \text { and } \\
57 \% \text { RH for } 5 \text { d. Plasma } \\
\text { volume and resting } T_{\text {int }} \text { were } \\
\text { measured prior to and fol- } \\
\text { lowing heat acclimation. }\end{array}$ & $\begin{array}{l}\text { EUH }(0.6 \%[0.7 \%] \text { BML }) \text { and } \\
\text { DEH }(2.7 \%[0.8 \%] \text { BML }) \\
\text { groups performed } 90-\text { min } \\
\text { exercise with isothermal } \\
\text { method in } 39^{\circ} \mathrm{C} \text { and } 56 \% \mathrm{RH} \\
\text { for } 8 \mathrm{~d} \text {. Adaptations in plasma } \\
\text { volume, HR, } T_{\text {int }}, T_{\text {skin }} \text { and } \\
\text { sweat loss were measured by } \\
\text { heat stress test prior to and } \\
\text { following heat acclimation. } \\
\text { HST was consisted of } 60 \text { min at } \\
35 \% \text { of peak power output in } \\
39^{\circ} \mathrm{C} \text { and } 53 \% \mathrm{RH} \text {. }\end{array}$ & $\begin{array}{l}\text { EUH (1.4\% BML) and DEH } \\
(2.4 \% \mathrm{BML}) \text { groups performed } \\
\text { for } 3 \mathrm{~d} \text { of } 90 \text {-min exercise at } \\
50 \% \mathrm{VO}_{2} \mathrm{max} \text { in } 40^{\circ} \mathrm{C} \text { and } 30 \% \\
\text { RH. Plasma volume, } \mathrm{HR}, T_{\text {skin }} \text {, } \\
\text { and sweat rate were measured } \\
\text { by heat stress test prior to and } \\
\text { following heat acclimation. } \\
\mathrm{HST} \text { was consisted of } 90 \text { min at } \\
50 \% \mathrm{VO}_{2} \mathrm{max} \text { in } 40^{\circ} \mathrm{C} \text { and } 30 \% \\
\text { RH. }\end{array}$ & $\begin{array}{l}\text { EUH }(-0.3 \%[0.6 \%] \text { BML }) \text { and } \\
\text { DEH }(1.9 \%[0.6 \%] \text { BML) } \\
\text { groups performed } 5 \mathrm{~d} \text { of } 90 \text { min } \\
\text { with isothermal method in } 35^{\circ} \mathrm{C} \\
\text { and } 60 \% \mathrm{RH} \text {. Plasma volume, } \\
\mathrm{HR}, T_{\text {int }} \text {, and } T_{\text {skin were mea- }} \\
\text { sured by HST prior to and fol- } \\
\text { lowing heat acclimation. HST } \\
\text { was consisted of } 90 \text { min at } 40 \% \\
\text { of peak power output in } 35^{\circ} \mathrm{C} \\
\text { and } 60 \% \mathrm{RH} \text {. }\end{array}$ \\
\hline $\begin{array}{l}\text { Outcome } \\
\text { measures }\end{array}$ & $\begin{array}{l}\text { Plasma volume } \\
\text { Resting } T_{\mathrm{int}}\end{array}$ & $\begin{array}{l}\text { Plasma volume } \\
\text { HR } \\
T_{\text {int }} \\
T_{\text {skin }} \\
\text { Sweat loss }\end{array}$ & $\begin{array}{l}\text { Plasma volume } \\
\text { HR } \\
T_{\text {skin }} \\
\text { Sweat rate }\end{array}$ & $\begin{array}{l}\text { Plasma volume } \\
\text { HR } \\
T_{\text {int }} \\
T_{\text {skin }}\end{array}$ \\
\hline
\end{tabular}


Table 2 (continued)

\begin{tabular}{|c|c|c|c|c|}
\hline Article & Pethick et al $^{6}$ & Neal et al ${ }^{11}$ & Schleh et al ${ }^{5}$ & Garrett et al $^{12}$ \\
\hline Main findings & $\begin{array}{l}\text { Plasma volume was not } \\
\text { different in EUH }(+4.8 \% \\
[10.2 \%]) \text { and } \mathrm{DEH}(+1.7 \% \\
[10.1 \%]) \text { following heat } \\
\text { acclimation }(P>.05) \text {. Rest- } \\
\text { ing } T_{\text {int }} \text { was not different in } \\
\text { EUH }\left(37.3^{\circ} \mathrm{C}\left[0.3^{\circ} \mathrm{C}\right]\right) \text { and } \\
\text { DEH }\left(37.4^{\circ} \mathrm{C}\left[0.3^{\circ} \mathrm{C}\right]\right) \\
\text { following heat acclimation } \\
(P>.05) \text {. }\end{array}$ & $\begin{array}{l}\text { Plasma volume, HR, } T_{\text {int, }} T_{\text {skin, }} \\
\text { and sweat loss were not differ- } \\
\text { ent in EUH and DEH following } \\
\text { heat acclimation. (Data in arti- } \\
\text { cle represented by figures.) }\end{array}$ & $\begin{array}{l}\text { Sweat rate increased greater } \\
\text { following heat acclimation with } \\
\text { DEH }\left(1.9[0.1] \mathrm{L}^{-1}\right) \text { com- } \\
\text { pared with EUH }(1.8 \\
\left.[0.1] \mathrm{L}^{-1}\right)(P=.02) \text {. There } \\
\text { were no differences in plasma } \\
\text { volume }(\mathrm{EUH}, 4.4 \% \text { [2.5\%]; } \\
\text { DEH, } 7.1 \%[1.8 \%]), \mathrm{HR}(\mathrm{EUH} \text {, } \\
167.4[3.7] \mathrm{bpm} ; \mathrm{DEH}, 164.1 \\
[4.4] \mathrm{bpm}), \text { and } T_{\text {skin }}(\mathrm{EUH}, \\
37.6[0.2] \text {, DEH, } 37.4[0.1]) \\
\text { between EUH and DEH } \\
(P>.05) .\end{array}$ & $\begin{array}{l}\text { Plasma volume }(\mathrm{EUH}, 4 \% \\
\text { [3\%]; DEH, } 8 \%[3 \%], P=.06) \\
T_{\text {int }}\left(\mathrm{EUH},-0.2^{\circ} \mathrm{C} ; \mathrm{DEH},\right. \\
\left.-0.4^{\circ} \mathrm{C}, P=.52\right) \text {, and } T_{\text {skin }} \\
\left(\mathrm{EUH},-0.3^{\circ} \mathrm{C} ; \mathrm{DEH},-0.4^{\circ} \mathrm{C},\right. \\
P=.15) \text { were not different in } \\
\text { EUH and DEH following heat } \\
\text { acclimation. However, HR with } \\
\text { DEH demonstrated a greater } \\
\text { extent of change }(-19 \mathrm{bpm}) \\
\text { compared with EUH }(-10 \mathrm{bpm}) \\
\text { following heat acclimation } \\
(P=.05) .\end{array}$ \\
\hline $\begin{array}{l}\text { Level of } \\
\text { evidence }\end{array}$ & 2 & 2 & 2 & 2 \\
\hline Validity score ${ }^{\mathrm{a}}$ & 6 & 7 & 7 & 6 \\
\hline Conclusion & $\begin{array}{l}\text { Dehydration did not affect } \\
\text { adaptations in plasma } \\
\text { volume and resting } T_{\text {int }} \\
\text { following heat acclimation. }\end{array}$ & $\begin{array}{l}\text { Dehydration did not affect } \\
\text { adaptations in plasma volume, } \\
\text { HR, } T_{\text {int }}, T_{\text {skin }} \text {, and sweat loss } \\
\text { following heat acclimation. }\end{array}$ & $\begin{array}{l}\text { Dehydration did not affect } \\
\text { plasma volume, HR, and } T_{\text {skin }} \\
\text { following heat acclimation. } \\
\text { However, sweat rate increased } \\
\text { greater following heat accli- } \\
\text { mation with dehydration. }\end{array}$ & $\begin{array}{l}\text { Dehydration did not affect } \\
\text { adaptations in plasma volume, } \\
T_{\text {int, }} T_{\text {skin }} \text { and sweat loss } \\
\text { following heat acclimation. } \\
\text { However, HR decreased greater } \\
\text { following heat acclimation with } \\
\text { dehydration. }\end{array}$ \\
\hline
\end{tabular}

Abbreviations: BM, body mass; BML, body mass loss; bpm, beats per minute; DEH, dehydration; EUH, euhydration; HR, heart rate; HST, heat stress test; RCT, randomized controlled trial; $\mathrm{RH}$, relative humidity; $T_{\text {int }}$, internal body temperature; $T_{\text {skin }}$, skin temperature; $\mathrm{VO}_{2}$ max, maximal oxygen consumption; $\mathrm{VO}_{2}$ peak, peak oxygen consumption.

${ }^{a}$ Validity score was measured by PEDro scale.

\section{Strength of Recommendation}

Based on the Oxford Centre for Evidence-Based Medicine Scale, Level 2 evidence exists.

\section{Implications for Practice, Education, and Further Research}

The results of the 4 studies included in this critically appraised topic demonstrate that hydration status does not change physiological adaptations in plasma volume, internal body temperature, and skin temperature. While heat acclimation protocols can vary, the studies that met the inclusion criteria had exercise trials in the heat from 3 to 8 days. The study to show differences in sweat rate had the shortest heat acclimation protocol. Trials were held over a 3-day period, which included exercising in the heat for 90 minutes 3 times a day. ${ }^{5}$ Plasma volume and heart rate remained unchanged. Sweat rate was the only variable that had changes between dehydrated $(1.5[0.1]$ to $\left.1.9[0.1] \mathrm{L} \cdot \mathrm{h}^{-1}\right)$ and euhydrated trials $\left(1.6[0.1]\right.$ to $1.8[0.1] \mathrm{L} \cdot \mathrm{h}^{-1}$, $P=.02$ ). In addition, only 1 study demonstrated greater changes in heart rate with dehydration trials following heat acclimation compared with preheat acclimation heart rate. However, the absolute heart rate values were not different between euhydration and dehydration trials following heat acclimation. As all 4 studies did not show changes in plasma volume, internal body temperature, and skin temperature, and 2 out of 3 studies did not indicate the differences in heart rate, between euhydrated and dehydrated trials, which indicates that intentional dehydration does not influence effectiveness of heat acclimation. When designing a heat acclimation protocol, researchers need to keep in mind the target population and ultimate training goal to optimize heat acclimation. Each study included healthy, aerobically fit participants. As hydration status has not been demonstrated to attenuate or enhance the ability to acclimate to the heat, the maintenance of euhydration is considered optimal to prevent athletes from the risk of heat illness and decreases in performance during heat acclimation induction.

\section{References}

1. Périard JD, Racinais S, Sawka MN. Adaptations and mechanisms of human heat acclimation: applications for competitive athletes and sports. Scand J Med Sci Sports. 2015;25(suppl 1):20-38. PubMed ID: 25943654 doi: $10.1111 /$ sms. 12408

2. Armstrong LE, Millard-Stafford M, Moran DS, Pyne SW, Roberts WO. American College of Sports Medicine position stand. Exertional heat illness during training and competition. Med Sci Sports Exerc. 2007;39(3):556-572. PubMed ID: 17473783 doi:10.1249/MSS. 0b013e31802fa199

3. Tyler CJ, Reeve T, Hodges GJ, Cheung SS. The effects of heat adaptation on physiology, perception and exercise performance in the heat: a meta-analysis. Sports Med. 2016;46(11):1699-1724. PubMed ID: 27106556 doi:10.1007/s40279-016-0538-5

4. Daanen HAM, Racinais S, Périard JD. Heat acclimation decay and re-induction: a systematic review and meta-analysis. Sports Med. 2018;48(2):409-430. PubMed ID: 29129022 doi:10.1007/s40279017-0808-x

5. Schleh MW, Ruby BC, Dumke CL. Short term heat acclimation reduces heat stress, but is not augmented by dehydration. $J$ Therm Biol. 2018;78:227-234. PubMed ID: 30509641 doi:10.1016/j. jtherbio.2018.10.004

6. Pethick WA, Murray HJ, McFadyen P, Brodie R, Gaul CA, Stellingwerff T. Effects of hydration status during heat acclimation on plasma volume and performance. Scand J Med Sci Sports. 2019;29(2):189-199. PubMed ID: 30317666 doi:10.1111/sms.13319 
7. Patterson MJ, Stocks JM, Taylor NA. Whole-body fluid distribution in humans during dehydration and recovery, before and after humidheat acclimation induced using controlled hyperthermia. Acta Physiol. 2014;210(4):899-912. PubMed ID: 24330400 doi:10.1111/ apha.12214

8. Garrett AT, Creasy R, Rehrer NJ, Patterson MJ, Cotter JD. Effectiveness of short-term heat acclimation for highly trained athletes. Eur J Appl Physiol. 2012;112(5):1827-1837. PubMed ID: 21915701 doi:10.1007/s00421-011-2153-3

9. Sawka MN, Burke LM, Eichner ER, Maughan RJ, Montain SJ, Stachenfeld NS. American College of Sports Medicine position stand. Exercise and fluid replacement. Med Sci Sports Exerc. 2007;39(2): 377-390. PubMed ID: 17277604 doi:10.1249/mss.0b013e31802ca597
10. Armstrong LE, Maresh CM, Gabaree CV, et al. Thermal and circulatory responses during exercise: effects of hypohydration, dehydration, and water intake. J Appl Physiol. 1997;82(6): 2028-2035. PubMed ID: 9173973 doi:10.1152/jappl.1997.82.6. 2028

11. Neal RA, Massey HC, Tipton MJ, Young JS, Corbett J. Effect of permissive dehydration on induction and decay of heat acclimation, and temperate exercise performance. Front Physiol. 2016;7:564. PubMed ID: 27932993 doi:10.3389/fphys.2016.00564

12. Garrett AT, Goosens NG, Rehrer NJ, et al. Short-term heat acclimation is effective and may be enhanced rather than impaired by dehydration. Am J Hum Biol. 2014;26(3):311-320. PubMed ID: 24469986 doi:10.1002/ajhb.22509 